\title{
Mutational Analysis Using Enriched PCR and Cycle Sequencing
}

BioTechniques 24:1028-1031 (June 1998)

\author{
Kent R. Mitchell and David \\ Warshawsky \\ University of Cincinnati \\ Medical Center, Cincinnati, \\ $\mathrm{OH}$, USA
}

During the course of our research on chemically induced mutational spectra in mouse skin and liver tumors, we found the need to develop a sensitive method that would screen out nonmutated genes, related genes and pseudogenes. Although cold single-strand conformation polymorphism methods that used intron-specific primers existed, these methods were only sensitive to the point of 1 mutant in 33 normal molecules $(7,8)$. We were able to substantially modify an enriched polymerase chain reaction (PCR) screening method, originally used to screen for K-ras codons 12 and 13 in human colon tumors $(5,6)$, to be used for H-ras codons 12 and 13 as well as codon 61 mutations in chemically induced mouse skin and liver tumors. Briefly, this method consisted of four steps: (i) primary amplification, (ii) intermediate digestion, (iii) secondary amplification and (iv) final digestion. Aliquots of the final digests were resolved on agarose gels rather than polyacrylamide gels as in the original procedure $(5,6)$. Mutant PCR products are cut once, whereas normal PCR products are cut twice by the codon-specific restriction endonuclease. This allows for an internal control upon digestion with the en- zymes. The procedure is outlined briefly in Table 1. Although this method was used to detect specific mouse $\mathrm{H}$-ras mutations, it could easily be adapted to detect point mutations within other genes and species such as the suspected aflatoxin-induced codon 249 mutation in the p53 gene in human liver or the suspected benzo[a]pyrene-induced codon $157 \mathrm{mu}$ tation in p53 in human lung tissue using the wide array of commercially available restriction endonucleases.

DNA was isolated from both normal and tumor-laden mouse skin and liver using Puregene ${ }^{\mathrm{TM}}$ reagents (Gentra Systems, Minneapolis, MN, USA) and proteinase $\mathrm{K}$ and quantitated by UV spectroscopy at $260 \mathrm{~nm}$. All PCR primers were based on the mouse H-ras genomic sequence of Brown et al. (2). All PCRs were carried out in a PTC-100 10 TM Programmable Thermal Controller (MJ Research, Watertown, MA, USA). Positive controls were prepared by amplifying $200 \mathrm{ng}$ of normal DNA using mutated $5^{\prime}$ primers and normal $3^{\prime}$ primers (Table 2; codons 12 and 13: primers 1 and 2; codon 61: primers 3 and 4 ) under the following conditions: $50 \mathrm{mM} \mathrm{KCl}$, $10 \mathrm{mM}$ Tris- $\mathrm{HCl}\left(\mathrm{pH} 9.0\right.$ at $\left.25^{\circ} \mathrm{C}\right)$, $0.1 \%$ Triton $^{\circledR} \mathrm{X}-100,0.2 \mathrm{mM}$ each dNTP, $2.0 \mathrm{mM} \mathrm{MgCl}_{2}$, $1 \mathrm{U}$ Taq DNA Polymerase (Promega, Madison, WI, USA) and $0.2 \mathrm{mM}$ each primer in a 50$\mu \mathrm{L}$ final volume, covered with $25 \mu \mathrm{L}$ of Chill-out $^{\mathrm{TM}} 14$ (MJ Research) and subjected to the following amplification protocol: initial denaturation at $94^{\circ} \mathrm{C}$ for $5 \mathrm{~min}$ and 35 cycles of denaturation at $94^{\circ} \mathrm{C}$ for $1 \mathrm{~min}$, annealing at $62^{\circ} \mathrm{C}$ for 2 min and extension at $72^{\circ} \mathrm{C}$ for $1 \mathrm{~min}$, with a final extension at $72^{\circ} \mathrm{C}$ for $2 \mathrm{~min}$.
PCR products (combined codons 12 and 13: 252 bp and codon 6: 226 bp) were purified on $2 \%$ MetaPhor $^{\circledR}$ agarose gels (FMC BioProducts, Rockland, ME, USA), extracted from the agarose using QIAEX ${ }^{\circledR}$ (Qiagen, Chatsworth, CA, USA), quantitated on $2 \%$ MetaPhor agarose gels using a Low DNA Mass Ladder (Life Technologies, Gaithersburg, MD, USA) and diluted to $15 \mathrm{pg} / \mu \mathrm{L}$ for further use. These positive controls contained a codon 12 mutation of GGA $\rightarrow$ GAA, a codon 13 mutation of GGC $\rightarrow$ GAC and a codon 61 mutation of $\mathrm{CAA} \rightarrow \mathrm{CGA}$.

Tumor DNA was screened for codon 12,13 and 61 mutations using the following protocol. Positive control (7.5

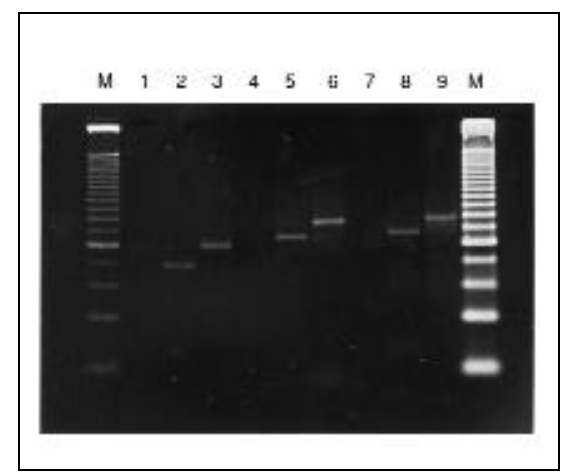

Figure 1. 3\% MetaPhor agarose/1× TBE electrophoresis gel showing H-ras codon 12, 13 and 61 null, negative and positive controls. Lanes $\mathrm{M}$ are 25-bp markers. Lane 1 is codon 12 null $\left(\mathrm{H}_{2} \mathrm{O}\right)$ control; lane 2 is codon 12 negative control (95 bp); lane 3 is codon 12 positive control (124 bp); lane 4 is codon 13 null control; lane 5 is codon 13 negative control (137 bp); lane 6 is codon 13 positive control (167 bp); lane 7 is codon 61 null control; lane 8 is codon 61 negative control (135 bp); and lane 9 is codon 61 positive control (162 bp). 
Table 1. Procedure Outline

1. Primary amplification of tumor DNA using $5^{\prime}$ and $3^{\prime}$ wt primers.

2. Initial restriction endonuclease digestion of primary amplification aliquot.

3. Secondary amplification of initial digestion aliquot using excess of $5^{\prime}$ and $3^{\prime}$ primers.

4. Final restriction endonuclease digestion of secondary amplification aliquot.

5. Resolution of final digestion products on $3 \%$ MetaPhor gel run in $1 \times$ TBE buffer (89 mM Tris-OH, 89 mM boric acid, 2 mM EDTA, pH 8.3).

6. Cut out positive bands.

7. Direct amplification of positive bands using $5^{\prime}$ and nested $3^{\prime}$ primers.

8. Amplification product cleanup and quantitation.

9. Reverse cyclic dideoxy sequencing using labeled further nested 3' primer.

pg), negative control (1 $\mu \mathrm{g}$ normal DNA) and a null control (sterile distilled $\mathrm{H}_{2} \mathrm{O}$ that had been treated with UV light was substituted for DNA) were included with each set of screening reactions. One microgram of tumor DNA was amplified using $10 \mathrm{ng}$ of each appropriate $5^{\prime}$ primer and 3'wt primer (Table 2; codon 12: primers 5 and 6, codon 13: primers 8 and 9 , codon 61: primers 11 and 12 ) in a $50-\mu \mathrm{L}$ volume containing $50 \mathrm{mM} \mathrm{KCl}, 10 \mathrm{mM}$ Tris$\mathrm{HCl}\left(\mathrm{pH} 9.0\right.$ at $\left.25^{\circ} \mathrm{C}\right), 0.1 \%$ Triton $\mathrm{X}$ $100,0.2 \mathrm{mM}$ each dNTP, $1.5 \mathrm{mM}$ $\mathrm{MgCl}_{2}$ and $1.5 \mathrm{U}$ Taq DNA polymerase, covered with $25 \mu \mathrm{L}$ Chill-out 14 and subjected to an initial denaturation at $94^{\circ} \mathrm{C}$ for $5 \mathrm{~min}$ and 20 cycles of denaturation at $94^{\circ} \mathrm{C}$ for $1 \mathrm{~min}$, annealing at $60^{\circ} \mathrm{C}$ for $1 \mathrm{~min}$ and extension at $72^{\circ} \mathrm{C}$ for $1 \mathrm{~min}$, with a final extension at $72^{\circ} \mathrm{C}$ for $3 \mathrm{~min}$. Aliquots of these amplification reactions were then di- gested with the appropriate restriction endonuclease as outlined. Five microliters of the primary amplification reaction were digested for $3 \mathrm{~h}$ with $1 \mu \mathrm{L}$ of restriction endonuclease (codon 12: Bst $\mathrm{OI}$ at $60^{\circ} \mathrm{C}$, codon $13: B g l \mathrm{I}$ at $37^{\circ} \mathrm{C}$, codon 61: $\mathrm{BclI}$ at $50^{\circ} \mathrm{C}$ ) (restriction endonucleases were from Promega) in $1 \times$ restriction endonuclease buffer (Promega) in a final volume of $10 \mu \mathrm{L}$, which is covered with $5 \mu \mathrm{L}$ Chill-out 14 .

These digested PCR products were then subjected to secondary amplification. One microliter of intermediate digest was amplified using $50 \mathrm{ng}$ of each appropriate $5^{\prime}$ and $3^{\prime}$ primer (Table 2; codon 12: primers 5 and 7, codon 13: primers 8 and 10, codon 61: primers 11 and 13 ) in reaction conditions identical to the primary amplification in a $50-\mu \mathrm{L}$ volume, covered with $25 \mu \mathrm{L}$ Chill-out 14 and subjected to an initial denaturation at $94^{\circ} \mathrm{C}$ for $5 \mathrm{~min}$ and 35 cycles of

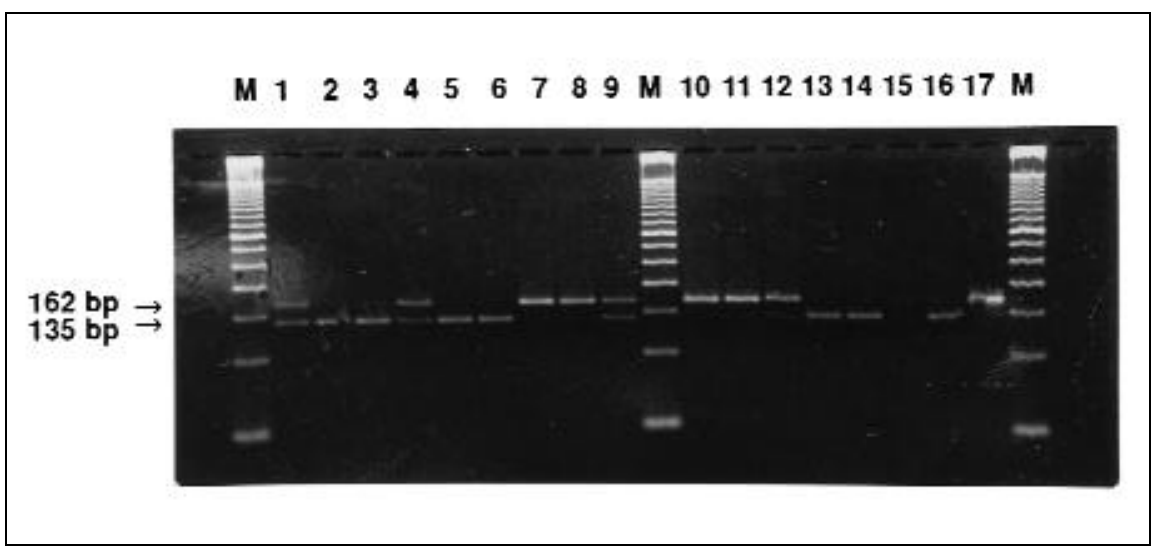

Figure 2. Example of H-ras codon 61 enriched PCR screening of DBC-induced skin and liver tumors. Positive: 162 bp; negative: 135 bp. Lanes M: 50-bp marker (Life Technologies). Lanes 1, 4, 7, 8, 9 , 10,11 and 12 contain positive bands (lanes 1,4 and 9 also contain negative bands); lane 15: water; lane 16: negative control; lane 17: positive control. Positive bands were excised, re-amplified and reversesequenced to determine site and type of mutation. 


\section{Cancer Research Techniques}

Table 2. Primers Used for H-ras Codon 12, 13 and 61 Mutant Controls, Enriched PCR, Re-amplification and Reverse Sequencing

\begin{tabular}{ll|}
\hline 1. HRAS 1213 mut-5': & GCTATGACAGAATACAAGCTTGTGGTGGTGGGCGCTGaAGaCGTGG \\
2. HRAS 1213 mut-3': & TCCACAGAACCAGCCTACACCCTTGCACCTCTGATACCCTGATGG \\
3. HRAS 61 mut-5': & GGGGAGACATGTCTACTGGACATCTTAGACACAGCAGGTCgAGAAG \\
4. HRAS 61 mut-3': & AGACATAAAGCCTCAGTGTGCACACGGAACCTTCCTCACGTGTGCC \\
5. HRAS 12-5': & ACAGAATACAAGCTTGTGGTGGTGGGCcCT \\
6. HRAS 12-3'wt: & AGCCCACCTCTGGCAGGTAG \\
7. HRAS 12-3': & AGCCCACCTCTGCCAGGTAG \\
8. HRAS 13-5': & AGAATACAAGCTTGTGGTGGTGGGCcCTGG \\
9. HRAS 13-3'wt: & CACCTACAAGACCTGGGCTGTTTGGTCA \\
10. HRAS 13-3': & CACCTACAAGACCTGGCCTGTTTGGCCATTTAC \\
11. HRAS 61-5': & TGTCTACTGGACATCTTAGACACAGCtGaT \\
12. HRAS 61-3'wt: & ACGTGTGCCAGGGCTCACGG \\
13. HRAS 61-3': & ACGTGTGCCAGtGaTCACGG \\
14. HRAS 1213 reamp: & AGCTCACCTCTATAG \\
15. HRAS 61 reamp: & CTGTACTGATGGATG \\
16. SEQ 1213R: & CTCTATAGTGGGATCATACTCGTCCAC \\
17. SEQ 61R: & GATGGATGTCCTCGAAGGACTTGGTG \\
All primers are listed in a 5' to 3' orientation. Lower-case letters indicate mutant bases. Underlined sequences indicate \\
restriction endonuclease sites or partial restriction endonuclease sites.
\end{tabular}


denaturation at $94^{\circ} \mathrm{C}$ for $1 \mathrm{~min}$, annealing at $60^{\circ} \mathrm{C}$ for $1 \mathrm{~min}$ and extension at $72^{\circ} \mathrm{C}$ for $1 \mathrm{~min}$ with a final extension at $72^{\circ} \mathrm{C}$ for $3 \mathrm{~min}$. These amplification reactions were ready for final digestion. Three microliters of secondary amplification reaction were digested for $6 \mathrm{~h}$ in a $10-\mu \mathrm{L}$ volume covered with $5 \mu \mathrm{L}$ of Chill-out 14 under the same conditions as the intermediate digests.

The final PCR digests were resolved on agarose gels as follows. Five microliters of digest were mixed with $5 \mu \mathrm{L}$ TE buffer (10 mM Tris-HCl, pH 7.5, 1 $\mathrm{mM}$ EDTA, $\mathrm{pH}$ 8.0) and $2.5 \mu \mathrm{L}$ dye buffer $(50 \%$ glycerol, $1 \mathrm{mM}$ EDTA, $0.25 \%$ xylene cyanol, $0.25 \%$ bromphenol blue and $0.4 \%$ orange $\mathrm{G}$ ) and loaded on a $3 \%$ MetaPhor agarose gel along with a 25-bp ladder (Life Technologies). The gels were run at $3.75 \mathrm{~V} /$ $\mathrm{cm}$ until the bromphenol blue reached the end of the gel. The gels were stained in ethidium bromide $(1 \mu \mathrm{g} / \mathrm{mL})$ for $20 \mathrm{~min}$ and destained in several changes of distilled $\mathrm{H}_{2} \mathrm{O}$ for $40 \mathrm{~min}$. The gels were photographed through a No. 2B Wratten filter on Type 667 or 55 instant film (Polaroid, Cambridge, MA, USA) at $f / 5.6$ for $0.5 \mathrm{~s}$. Figure 1 shows a 3\% MetaPhor agarose gel loaded with codons 12,13 and 61 null, negative and positive controls. Mutant codon 12 DNA showed a 124-bp PCR product, whereas normal DNA showed a 95-bp PCR product. Codon 13 gave a 167-bp mutant product and a 137-bp normal product. Codon 61 gave a 162bp mutant product and a 135-bp normal product. Mutant bands in the gel were cored out using a plugged genomic pipet tip and were directly amplified without further purification.

Small amounts of cored positive bands (approximately $10 \mu \mathrm{L}$ ) were reamplified in a $50-\mu \mathrm{L}$ volume using 10 nmol of appropriate $5^{\prime}$ and re-amplification primers (Table 2; codon 12: primers 5 and 14, codon 13: primers 8 and 14, codon 61: primers 11 and 15) under the previously described secondary amplification conditions and the following protocol: initial denaturation at $94^{\circ} \mathrm{C}$ for $5 \mathrm{~min}$ followed by 35 cycles of denaturation at $94^{\circ} \mathrm{C}$ for $1 \mathrm{~min}$, annealing at $55^{\circ} \mathrm{C}$ for $1 \mathrm{~min}$ and extension at $72^{\circ} \mathrm{C}$ for $1 \mathrm{~min}$, with a final extension at $72^{\circ} \mathrm{C}$ for $3 \mathrm{~min}$. Re-amplified codon 12 mutants gave 115 -bp prod- ucts, codon 13 mutants gave 113-bp products, and codon 61 mutants gave 140-bp products. These re-amplified products were purified using Wizard ${ }^{\circledR}$ PCR Preps (Promega) and quantitated on 3\% MetaPhor agarose gels using a Low DNA Mass Ladder.

Forty femtomoles of mutant reamplified PCR product were reversesequenced using the $\mathrm{fmol}^{\circledR}$ DNA Cycle Sequencing System (Promega) and sequencing primers labeled with $[\gamma$ 32P]ATP (NEN Life Science Products, Boston, MA, USA) (Table 2; codons 12 and 13: primer 16, codon 61: primer 17) under the following amplification parameters: initial denaturation at $94^{\circ} \mathrm{C}$ for $5 \mathrm{~min}$ followed by 30 cycles of denaturation at $94^{\circ} \mathrm{C}$ for $30 \mathrm{~s}$ and extension at $72^{\circ} \mathrm{C}$ for $30 \mathrm{~s}$ for codon 12 and 13 mutants. Codon 61 mutants required a $74^{\circ} \mathrm{C}$ annealing/extension temperature. Sequencing products were resolved on a $6 \%$ SequaGel $^{\mathrm{TM}}$ (National Diagnostics, Atlanta, GA, USA), covered with plastic wrap, dryed onto No. 1 filter paper (Whatman International Ltd., Maidstone, Kent, England, UK) and exposed to X-ray film (X-Omat AR; Scientific Imaging Systems [Eastman Kodak], New Haven, CT, USA) for $12-18 \mathrm{~h}$.

This method has proven to be very sensitive for initial screening of chemically induced mouse skin and liver tumors. We have used this method to analyze $7 \mathrm{H}$-dibenzo[c,g]carbazole (DBC)induced skin and liver tumors (Figure 2), which showed a CAA $\rightarrow$ CTA codon 61 mutation exclusively, and benzo[a]pyrene-induced skin tumors, which showed GGA $\rightarrow$ GTA codon 12 mutations and GGC $\rightarrow$ GTC codon 13 mutations. We are presently adapting this method further for $\mathrm{K}$-ras and N-ras mouse tumor screening. Although we have used this method to detect specific point mutations within the mouse genome, this method could be easily adapted to detect point mutations within other genes and species, e.g., by using Bsu36I (New England Biolabs, Beverly, MA, USA) to detect the suspected aflatoxin-induced p53 codon 249 mutation in human liver tumors $(1,4)$ or by using AatII (New England Biolabs) to detect the suspected benzo[a]pyrene-induced p53 codon 157 mutation in human lung tumors (3).

\section{ACKNOWLEDGMENTS}

This work was supported by National Institutes of Health Grants Nos. 2P01-ES05652-06, 5R01-ES04203-09, 5T32-ES07250 and 1P30-ES06096-05.

\section{REFERENCES}

1.Bressac, B., M. Kew, J. Wands and M. Ozturk. 1991. Selective G to T mutations of p53 gene in hepatocellular carcinoma from southern Africa. Nature 350:429-431.

2.Brown, K., B. Bailleul, M. Ramsden, F. Fee, R. Krumlauf and A. Balmain. 1988. Isolation and characterization of the $5^{\prime}$ flanking region of the mouse c-Harvey-ras gene. Mol. Carcinog. 1:161-170.

3.Denissenko, M.F., A. Pao, M.-S. Tang and G.P. Pfeifer. 1996. Preferential formation of benzo[a]pyrene adducts at lung cancer mutational hotspots in p53. Science 274:430-432.

4.Hsu, I.C., R.A. Metcalf, T. Sun, J.A. Welsh, N.J. Wang and C.C. Harris. 1991. Mutational hotspot in the p53 gene in human hepatocellular carcinomas. Nature 350:427-428.

5.Kahn, S.M., W. Jiang, T.A. Culbertson, I.B. Weinstein, G.M. Williams, N. Tomita and Z. Ronai. 1991. Rapid and sensitive nonradioactive detection of mutant k-ras genes via 'enriched' PCR amplification. Oncogene 6:10791083.

6.Ronai, Z., F.C. Luo, S. Gradia, W.J. Hart and R. Butler. 1994. Detection of k-ras mutation in normal and malignant colonic tissues by an enriched PCR method. Int. J. Oncol. 4:391-396.

7.Sipowicz, M.A., C.M. Weghorst, Y.-H. Shiao, G.S. Buzard, R.J. Calvert, M.R. Anver, L.M. Anderson and J.M. Rice. 1997. Lack of p53 and ras mutations in Helicobacter hepaticus-induced liver tumors in $\mathrm{A} / \mathrm{JCr}$ mice. Carcinogenesis 18:233-236.

8.Wang, D., C.M. Weghorst, R.J. Calvert and G.D. Stoner. 1996. Mutations in the p53 tumor suppressor gene in the rat esophageal papillomas induced by N-nitrosomethylbenzylamine. Carcinogenesis 17:625-630.

Received 1 December 1997; accepted 11 March 1998.

Address correspondence to:

Dr. Kent R. Mitchell

University of Cincinnati Medical Center

College of Medicine

Department of Environmental Health

PO Box 670056

Cincinnati, OH 45267-0056, USA

Internet: mitchekm@email.uc.edu 